\title{
Design and Implementation of Real-Time Monitoring System for Solar Power Plant in Surabaya, Indonesia
}

\author{
Ridho Hantoro ${ }^{1, *}$, Erna Septyaningrum ${ }^{1}$, Iwan Cony Setiadi ${ }^{1}$, Mokhammad Fahmi \\ Izdiharrudin $^{1}$, Pierre Damien Uwitije ${ }^{1}$, Aryeshah Akbar ${ }^{1}$, Naufal Hanif Rahmawan ${ }^{1}$, \\ and Lutfan Sinatra ${ }^{2}$ \\ ${ }^{1}$ Engineering Physics Department, Institut Teknologi Sepuluh Nopember, Jl. Teknik Kimia, Surabaya, \\ East Java, 60111, Indonesia \\ ${ }^{2}$ Division of Physical Sciences and Engineering (PSE), KAUST Solar Center, Materials Science and \\ Engineering, King Abdullah University of Science and Technology (KAUST), Thuwal, 23955-6900, \\ Saudi Arabia
}

\begin{abstract}
Availability of renewable energy now makes solar energy the right choice because of its advantages and easy application compared to other renewable energy sources. Monitoring of the output parameters of solar power plants needs to be done to assess the performance and efficiency of a solar power plant in real environmental conditions. The aims of research is to provide a direct and real time monitoring. This research has been carried out in solar power plants at Engineering Physics Department, FTI-ITS. The design of an ATmega32 microcontroller-based system that is integrated with Raspberry-pi as a data acquisition system. Data reading solar power plants output parameters stored in memory can be downloaded at any time. The analysis result shows that the efficiency of photovoltaic arrays is $10.78 \%$. The total efficiency of the solar power plants system is $8.05 \%$.
\end{abstract}

Keywords: Direct monitoring, performance of solar power plant, photovoltaic integration, renewable energy sources, solar energy.

\section{Introduction}

Indonesia, as a developed country, have promoted policies and initiatives to achieve sustainability by reducing energy dependence and emissions. These initiatives has a goal to limit climate change and lead to a decarbonized energy system in this future life, people's dependence on electricity, is the same as other basic human needs [1]. The world energy crisis and the high price of energy sources (oil) have led to innovations in the use of inexpensive alternative energy sources that are environmentally friendly such as solar energy. Public awareness that is supported by the geographical conditions of Indonesia which is located on the equator creates developments in technology development and innovation related to solar energy [2].

\footnotetext{
*Corresponding author: hantoro@ep.its.ac.id
} 
The main component of a solar power plant is a photovoltaic (PV) that can convert solar energy into electrical energy. The development of PV technology continues to experience progress, but not for optimization, monitoring and management technology, so it is not surprising if there are solar power plant that have experienced degradation in efficiency and even lost their conversion capability due to negligence of their owners [3].

Nowadays, the integration of PV power plants into existed power systems faced certain technical problems, mainly focused on reliability, power quality, and stability [4]. In addition, real-time monitoring technologies is needed to provide relevant local and accurate information to ensure the control and reliability of the system [5]. Periodic monitoring is needed to determine the performance of solar power plant from time to time, considering the efficiency of photovoltaic is strongly influenced by solar irradiance and the conditions of solar power plant itself. Optimization of power generation of a solar power plant can be done by evaluating the performance of the parameters from photovoltaic, such as fill factor, Voc, Isc and max-power [6]. Solar power plant is designed for long time use because investment is not cheap, therefore it is important to know the I-V characteristics of the solar power plant to plan preventive actions so that the Solar Power Plant continues to work optimally. According to Colak et al. [7], the current power systems should be modernized in terms of sensing, communication, measurement, and automation technologies.

On the topics of PV monitoring systems, some efforts can be found in the specific literature [3, 5-11]. Low-cost solutions have been considered as a priority solution during the last decade $[3,5]$, especially for developed country like Indonesia. There are researcher who proposed a microcontroller based solar monitoring system. Kabalci, Gorgun and Kabalci [11] introduces a real-time monitoring system of a renewable energy generation plant that is constituted with a wind turbine and solar panel arrays. The monitoring platform is based on current and voltage measurements. Nkoloma, Zennaro and Bagula [10] have also completely developed a novel monitoring and control system of a hybrid "wind PV battery' for renewable energy system. The proposed system is capable to collect a-real time measurement of electrical data (voltage and current) that can be effectively transferred to remote monitoring center by using intranet. Some low-cost data acquisition system is also proposed using a dedicated personal computer (PC) with USB for communication $[6,8]$. Another solution based on wired/wireless sensor-network technologies for solar-panel monitoring is discussed in $[9,12]$. The proposed architecture used low-cost open-source tools based on an Arduino or Raspberry Pi platform.

Previously, a pico solar power plants were developed in the ITS Engineering Physics Department (Surabaya, East Java, Indonesia) [6]. According to previous works, this paper proposes a flexible, low-cost, and user-friendly monitoring system based on Arduino and Raspberry Pi. The main objective of this research was to design a monitoring system to prevent the battery or PV panel damage or irregular use of a pico solar energy system. A local webpage were also developed to display data logging without requiring any internet connection. According to Meliones and Nouvaki [13] web-based real-time monitoring systems have been heavily used in industrial sectors for many years. It can be studied in order to gain significant experience in diverse application requirements.

The rest of the paper is written systematically as follows: Section 2 describes a detailed information about the proposed low-cost monitoring solution. Section 3 describes experimental field tests. The results and assessment of the proposed solution are also included in this section. Finally, the conclusion is given in Section 4. 


\section{Solar power plant monitoring system}

\subsection{Solar power plant performance calculation}

Since the Solar Power Plant consist of several component, the performance of each component contributes to the overall solar power plant efficiency. The calculation of overall solar power plant performance is given in Equation 1.

$$
\eta=\eta_{p v} \times \eta_{\text {batt }} \times \eta_{s c c} \times \eta_{i n v}
$$

Equation 1 clearly show that the overall performance is the accumulation of PV efficiency, battery efficiency, solar charge controller efficiency and inverter efficiency. The individual efficiency of PV, Solar charger controller, and inverter is the ratio of the output power $\left(P_{\text {out }}\right)$ and input power $\left(P_{\text {in }}\right)$ of each component, mathematically given by Equation 2.

$$
\eta_{P V, s s c, i n v}=\frac{P_{o u t}}{P_{\text {in }}} \times 100 \%
$$

PV input power can be expressed as multiplication of irradiance (Ir) in $\mathrm{W} \mathrm{m}^{-2}$ and area (A) with $\mathrm{m}^{-2}$ units capable of capturing irradiance emitted by sunlight. Meanwhile, the PV output power is the multiplication of open circuit voltage $\left(\mathrm{V}_{\mathrm{oc}}\right)$ and the short circuit current $\left(\mathrm{I}_{\mathrm{sc}}\right)$. The calculation of battery efficiency is carried out by using Equation 3, where Cd is discharging capacity and $\mathrm{Cc}$ is charging capacity.

$$
\eta_{\text {batt }}=\frac{C_{d}}{C_{c}} \times 100 \%
$$

\subsection{Monitoring system configuration}

The Figure 1 shows the configuration of solar power plant monitoring system. Photovoltaic array output in the form of DC voltage is collected and connected to the Solar Charge Controller (SSC). The SSC optimize the charging process of the battery as the storage system. The inverter converts the DC current to AC current, hence that can be used by the load. There are several electronic components for safety function. At the photovoltaic output mounted arresters that function to prevent excessive voltage so that it does not exceed the maximum input voltage from the Solar Charge Controller. At the output from the battery to the DC bus bar there is a MCCB (Molded Case Circuit Breaker) that serves to prevent excessive backflow which can cause damage to the battery when receiving excess current. Likewise from the AC bus bar that goes to the load there is also a surge arrester that can prevent excess voltage so that the excess voltage does not damage the load [6].

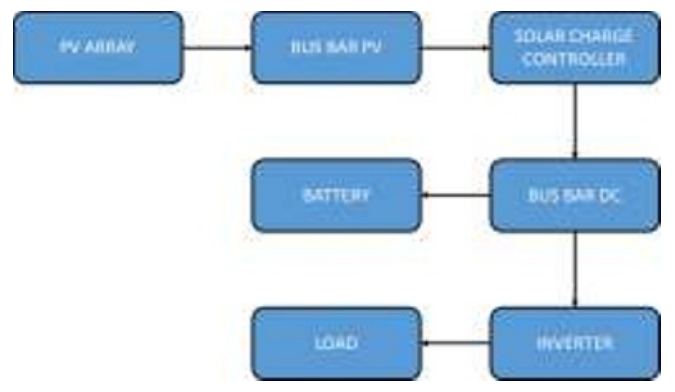

Fig. 1. Solar power plant monitoring system diagram. 


\subsection{Monitoring system assembly}

Arduino and Raspberry $\mathrm{Pi}$ are well-known low-cost, open-source, and extensibleprototyping solutions, allowing to provide a detailed monitoring system at PV-module level $[5,15]$. The Arduino is used to display the readings of the current and voltage sensors into the LCD, receive data from the weather station and send data in the form of sensor readings as well as data that has been received from the weather station to the Raspberry Pi which will then be uploaded to the website. Arduino boards usually consists of an onboard power supply, USB ports, and an ATMEL microcontroller chip. There are kind of sensors and additional components which are can be integrated through custom library and drive support by the manufacturers with the Arduino. On other hand, Raspberry Pi is the name of a series of single-board computers made by the Raspberry Pi Foundation. It has many advantages especially in terms of low cost, compact, full customization, and great scalability [5].

The block diagram of the interfacing system on the microcontroller is shown in Figure 2. The main microcontroller was connected to the voltage and current sensor for processing the raw data. A wide range of sensors are currently available for electrical monitoring under low-cost requirements.

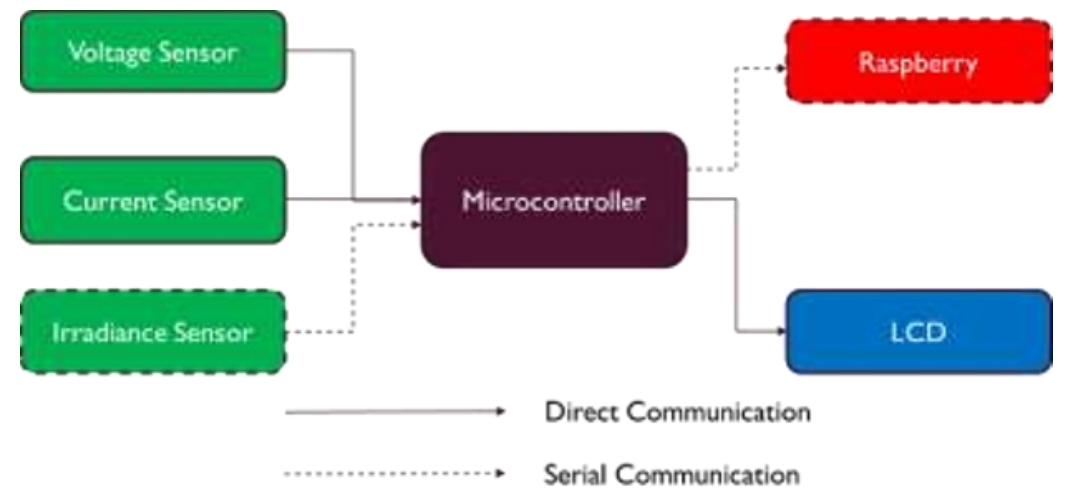

Fig. 2. Microcontroller interfacing.

For current measurements, ACS712 20A is used. This device consists of a series of precision, low offset, linear Hall sensors with copper conduction lines located near the die surface [9]. The applied current that flows through the copper conduction path produces a magnetic field that is sensed by the integrated IC Hall and is converted into proportional voltage.

The voltage divider is employed for the voltage sensor. Liquid Crsytal Display (LCD) $16 \times 2$ is used as a main display device and is installed on remote site. The navigation buttons are also installed on the system for user. Figure 3 shows the the developed system and its components. There are microcontroller board, sensors, LCD shields and navigation buttons, FTDI, and power supply.

A solar power plant monitoring website was successfully developed, which is used to display data or monitor the PV-VP performance, that can be seen on Figure 4. The real-time data is collected from the sensor installed in the solar power plant site. A web-server interface is included to provide external client connection and monitoring. A special page 
is added to provide information about irradiance, PV input power, PV output power, charging power, load power, and PV efficiency.

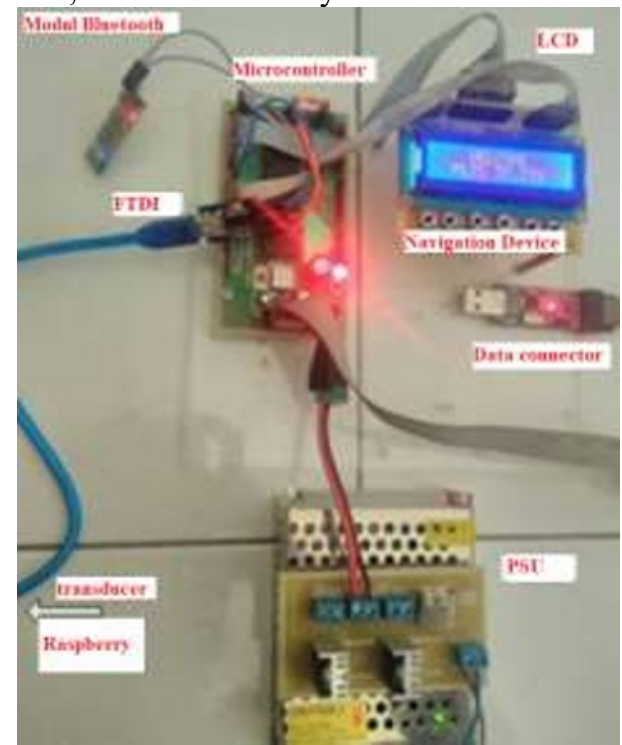

Fig. 3. Hardware set-up.
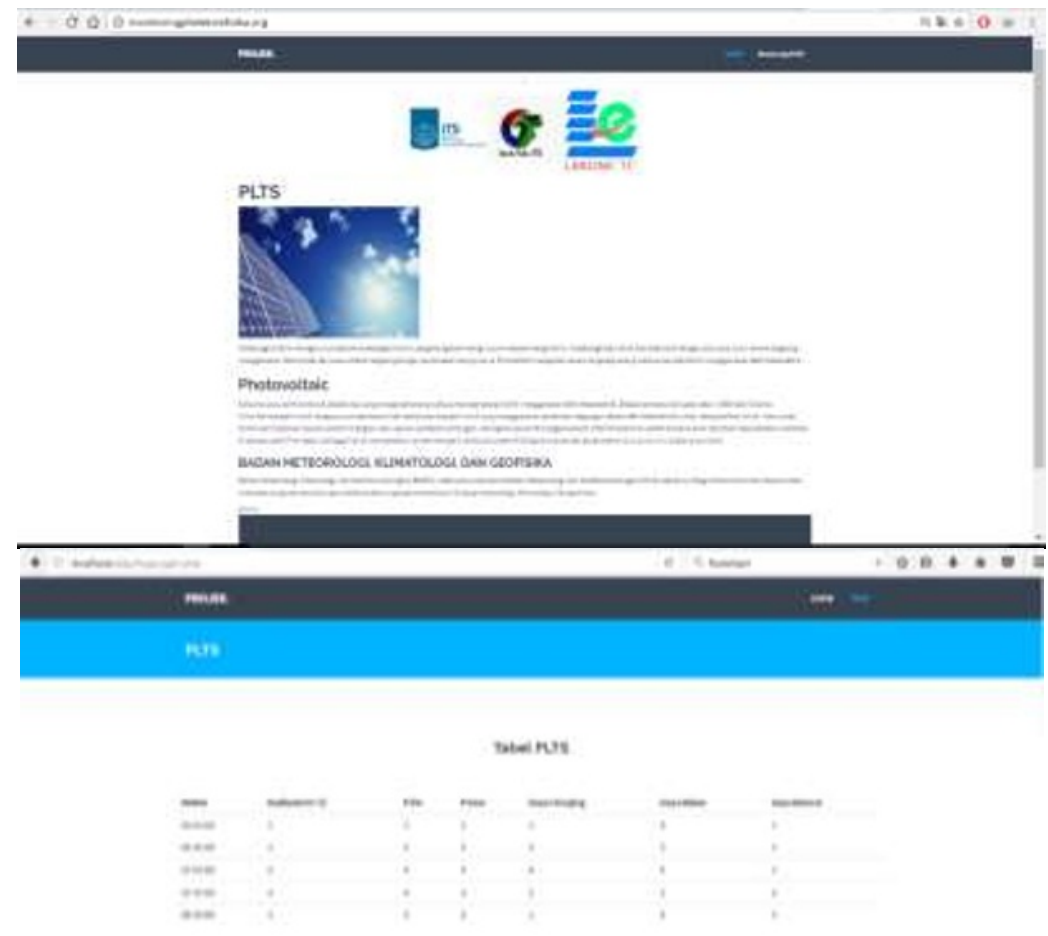

Ges Gove Wr

Fig. 4. Webserver. 


\subsection{Performance testing}

The proposed system has been tested and assessed in power plant under real conditions after the calibration system assembly. The communication network test is carried out by calculating the Quality of Service (QoS) parameters. QoS parameter measurement results consist of throughput, delay and packet loss. Throughput can be interpreted as actual actual bandwidth when sending data. Delay/Latency can be interpreted as the waiting time needed when sending data. The smaller the delay value means the quality of the network is getting better, and vice versa the network that has a large delay value indicates the network has poor quality. Packet loss is the failure of one or more transmitted packets to arrive at their destination [14].

The next step is data collection from the solar power plant and the proposed monitoring system within $36 \mathrm{~h}$. After obtaining solar power plant performance data and weather data for $36 \mathrm{~h}$, the data are grouped according to the data needed and taken an hourly average. Solar power plan data includes power data generated by photovoltaics, power data for charging batteries and power data used by inverters to supply the energy needs of the load. While the weather data includes irradiance data, PV surface temperature, ambient temperature and humidity. The performance of a solar power system is greatly influenced by many factors, including system components (PV, solar charge controllers, battery, inverters) and environmental conditions (solar irradiance, surface temperature and environmental temperature) [16].

\section{Results and discussion}

\subsection{Communication testing results}

A local webpage is developed to display data logging without requiring any internet connection. The QoS parameter is calculated to test the performance of web service and the connection. It consists of throughput, delay and packet loss. According to measurement data, the average value of throughput of $0.608 \mathrm{Kbps}$ or $608.22 \mathrm{Bps}$. The average delay is only $0.46 \mathrm{~ms}$, thus indicating that the latency category in the network has an excellent grade because the delay value obtained is less than $150 \mathrm{~ms}$. The minimum average delay is $0.18 \mathrm{~ms}$ and the maximum delay is $1.49 \mathrm{~ms}$. The packet loss obtained is $0 \%$. The packet loss does not occur because the host system uses Transmission Control Protocol (TCP) which has a retransmission mechanism in case of failure. TCP plays an importance role in improving the correct data transmission from a client to the server. TCP could detect errors or lost data and then retransmit it until the data is received correctly and completely. The results displayed from the web and LCD is compared, with 80 times data comparison. Data compared includes PV power, Charging power, battery power, and load power. The average accuracy of the overall score is $91 \%$.

\subsection{Effect of irradiance and temperature on PV array output}

Due to high influence of solar iradiance, PV temperature and the ambient temperature on the PV performance, this parameter should be monitored and analysis to get the best operating condition. The designed monitoring system is able to collect and represent the effect of this parameter on PV perfomance.

The solar irradiance is the major factor which determine the PV input power, as long as it has great effect on PV output power. The PV input power is the multiplication of solar irradiance and the PV surface area. The PV input power is increase as the solar irradiance 
increase, the same for the PV output power, as depicted in Figure 5. The highest PV output power is at $10.30 \mathrm{WIB}$, with PV outpot power of $288.96 \mathrm{~W}$ and solar irradiance of $467.62 \mathrm{~W} \mathrm{~m}^{-2}$. There was an increase in PV output power accompanied by an increase in the solar irradiance at $05.00 \mathrm{WIB}$ to $08.00 \mathrm{WIB}$ [(WIB = Waktu Indonesia Barat $)-$ West Indonesia Time], meanwhile the PV out power is decrease at $12.00 \mathrm{WIB}$ to $16.00 \mathrm{WIB}$ as the solar irradiance decrease. This increase and decrease is not linear because the output power of the photovoltaic array is not only influenced by irradiance, but also other environmental conditions such as ambient temperature, surface temperature and the characteristics of the constituent components of the solar power plant. At 10.00 WIB to 12.00 WIB high PV output power was obtained, indicating that the Solar charge controller supplies large amount of power for charging. Due to this condition, the battery is charged optimaly with large power. The solar charge controller will automatically operate in bulk mode because it detects a lack of power in the battery, so the solar charge controller tries to speed up battery charging.

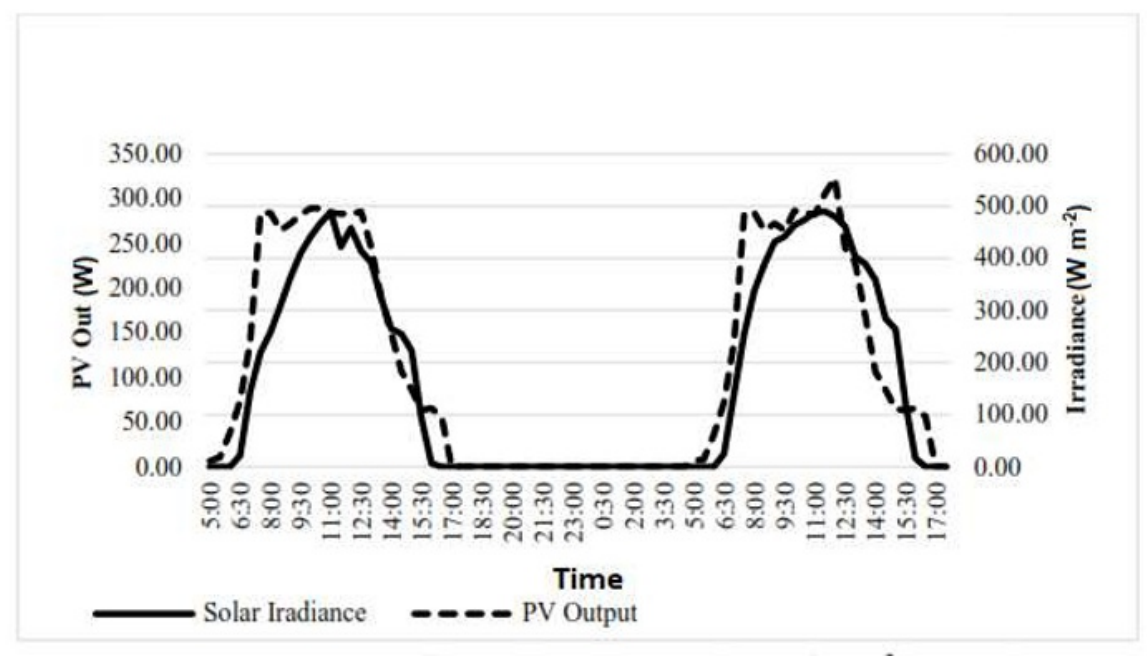

Fig. 5. PV out and irradiance data.

On the other hand, the increasing of surface temperature causes the decreasing of PV output power. The increase in the surface temperature of the photovoltaic array is accompanied by a decrease in the efficiency of the photovoltaic array (at $08.30 \mathrm{WIB}$ to 10.00 WIB) as shown in Figure 6. The same phenomenon occur at 11:30 WIB to 13:00 WIB, the decrement of surface temperature is followed by the increament of PV efficiency. This proves that the surface temperature is inversely proportional to the efficiency of the photovoltaic array. It can be concluded that the increase in solar irradiance affects the power production of the photovoltaic array. The greater the value of solar irradiance, the greater the production of photovoltaic array output power, conversely the smaller the value of solar irradiance, the smaller the power produced by the photovoltaic array. At the time of 10:00 WIB to 11:30 WIB where the efficiency should have increased because the surface temperature dropped, but the efficiency data taken actually increased, this also occurred in the time span of 13.00 WIB to 15.00 WIB. This shows that there are other factors that influence efficiency besides surface temperature, i.e. ambient temperature and wind speed. The wind speed here acts as a cool surface temperature of the photovoltaic array. The higher the wind speed, the better the efficiency of the photovoltaic array obtained. 


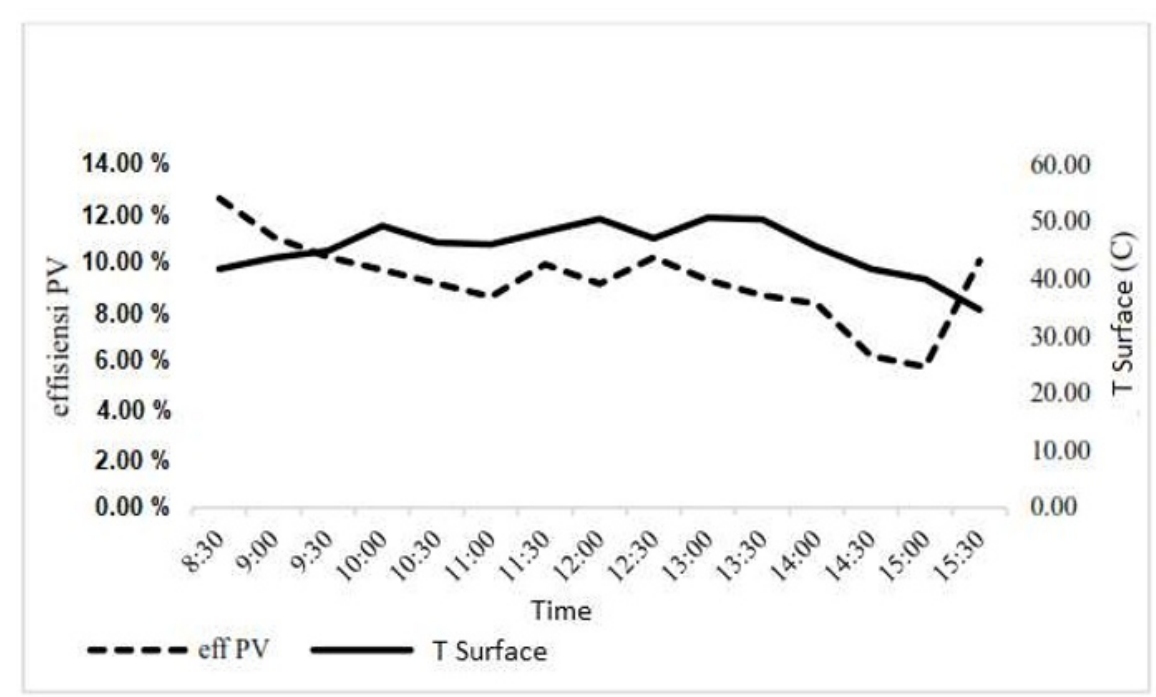

Fig. 6. Surface temperature and photovoltaic efficiency data.

At 9:00 WIB, the photovoltaic array has an efficiency of $11.05 \%$ when the ambient temperature is low at $30{ }^{\circ} \mathrm{C}$, the longer until 10.30 WIB there is an increase in environmental temperature, otherwise the value of the photovoltaic array efficiency decreases. At 10.30 WIB to $11.00 \mathrm{WIB}$, the PV array efficiency is decrease as the ambient temperature decrease. Similarly, at 12:30 WIB to 15:00 WIB there was a decrease in the efficiency of the photovoltaic array accompanied by a decrease in ambient temperature. This shows that environmental temperature has an indirect effect on the efficiency of photovoltaic arrays, besides the efficiency of photovoltaic arrays is directly influenced by several factors such as solar irradiance and surface temperature.

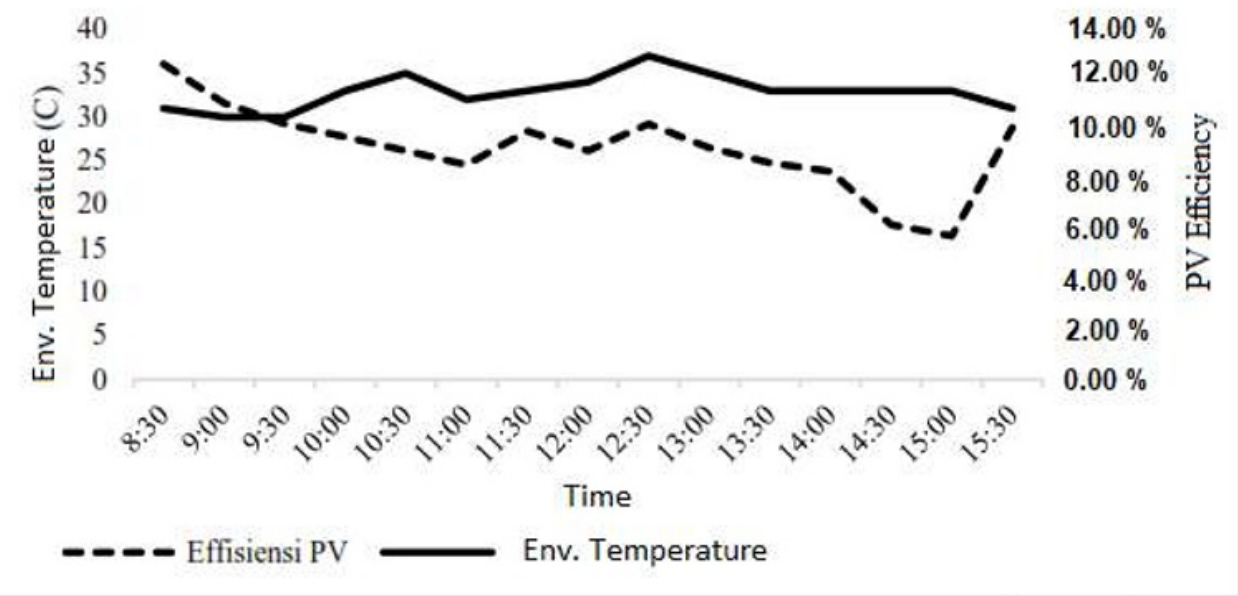

Fig. 7. Environmental temperature and photovoltaic efficiency data. 


\subsection{Solar power plant performance}

Comprehensive analysis for each componen of solar power plant system is needed to know the performace of the whole system. The component of solar power plant system is given in Figure 1. The performance of PV, solar power control, battery and inverter will be analyzed individually to get the overall performance of solar power plant.

The PV array loss take the major roles in the system losses calculation, hence the PV performance analysis needs attantion. The total solar input obtained on the two days of data collection was $42802.96 \mathrm{Wh}$ or $42.8 \mathrm{kWh}$, with the first day solar input of $20155.73 \mathrm{Wh}$ and for the second day of $22647.23 \mathrm{Wh}$. Maenwhile, the total PV output on the two days is $4262.97 \mathrm{Wh}$, i,e $2164.16 \mathrm{Wh}$ at the first day and $2098.80 \mathrm{Wh}$ at the second day, shown in Figure 8. The calculation of PV efficiency is carried out by using Equation 2. It confirmed that the PV array efficiency is $10.78 \%$.

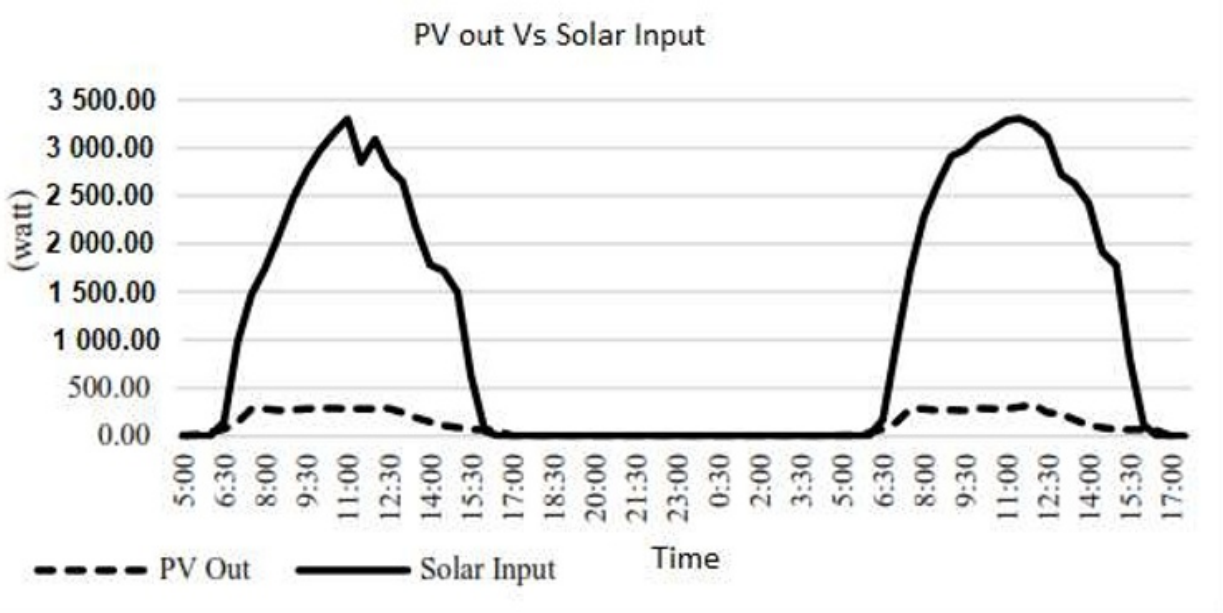

Fig. 8. PV output and solar input (irradiance) data

The PV power production and the used power by the load is given in Figure 9. This figure confirmes that the PV only used by the load in the night. The energy produced by PV during the day is stored in the battery system and used by the load at night. The load consumption power is stable at $143.6 \mathrm{~W}$. The total PV output is $2171.83 \mathrm{Wh}$, while the load consumption is $1475.35 \mathrm{Wh}$, hence the PV array module performance is $67.93 \%$. It means that the PV array supply $67.93 \%$ of its generated power to the load.

The efficiency of the solar charge controller is obtained from the comparison of the power generated for charging (power from PV array) with the power used for battery charging. The power generated for charging is $1914.36 \mathrm{~W}$, while the power used by charging to the battery is $1688.56 \mathrm{~W}$, hence, the efficiency of the solar charge controller is $88 \%$.

The battery efficiency is the comparison of the charging capacity and the discharge capacity. In the solar power plants operating cycle for $24 \mathrm{~h}$, the charging and discharging time is the same, ie $12 \mathrm{~h}$ of discharge and $12 \mathrm{~h}$ of charge as long as the load used is only active at night for lighting. At the time of discharging (discharging), the battery will issue a constant current, which is approximately $10.67 \mathrm{~A}$. The battery discharge capacity is $128.04 \mathrm{Ah}$. Meanwhile, the charging current tends to change 
depending on the solar charge controller performance to optimize the charging process. During charging, the battery charging current is approximately $12.43 \mathrm{~A}$. The charging capacity is $149.2 \mathrm{Ah}$. Using Equation 3, the battery efficiency is $86 \%$.

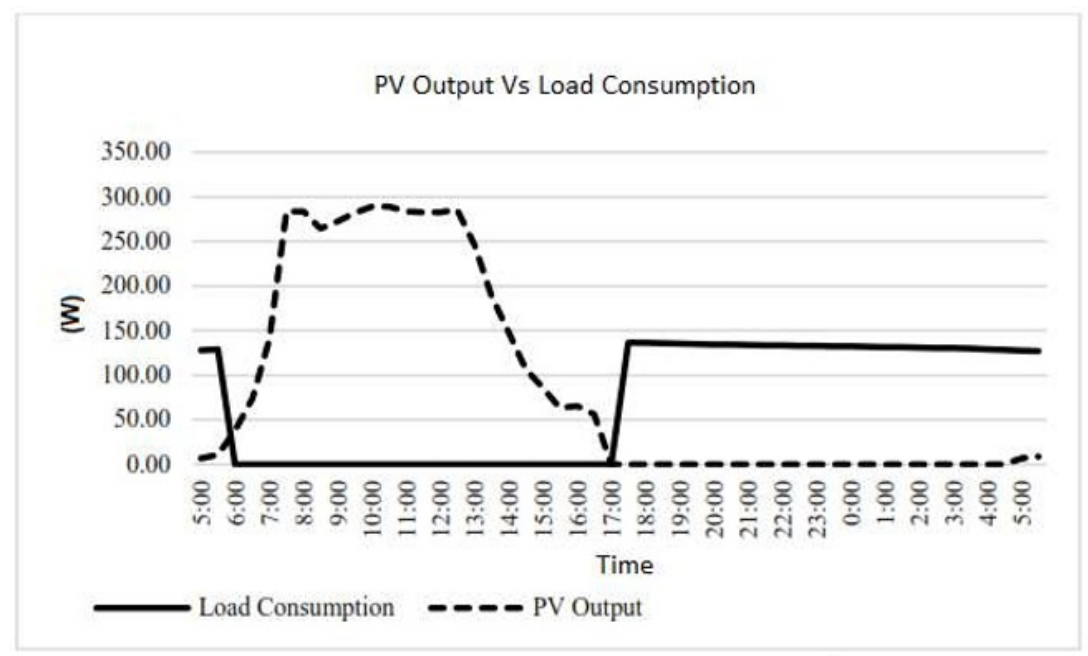

Fig. 9. PV output and load consumption data

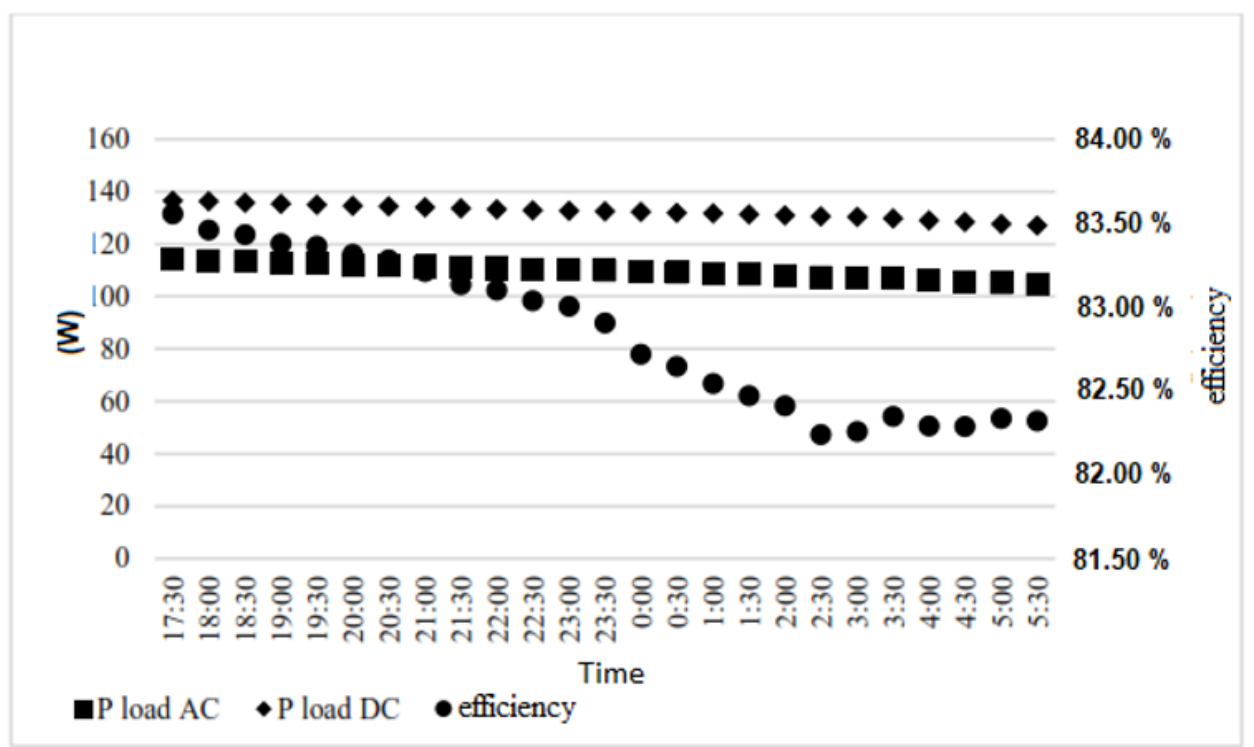

Fig. 10. Inverter performance.

The data from the inverter input power and the inverter output power is employed to find out the performance and efficiency of the inverter. The Equation 2 is used to calculate the inverted efficiency. The function of inverter is to convert the DC power from the battery to the AC power supplied to the load. Hence the input power of the inverter is the power DC power, which is get from the battery system, meanwhile the output power is the supplied AC power to the load. The load of this solar power system is 2-paralled LED 
floodlights with total power of $200 \mathrm{~W}$. When the data collection proses was conducted, the measured power is $142.6 \mathrm{~W}$, with the voltage of $230 \mathrm{VAC}$ and the current of $0.62 \mathrm{~A}$. By considering the load specification, the installed load is a non-linear load, which has a distorted output waveform. In other words, the waveform of the current and the output voltage are not the same as the input wave. In addition, the electronic ballast of the lamp stabilizes the current to minimize the used power and optimize the intensity of the emitted light. By using this type of ballast, the load has a high-power factor/pf (cos phi). The inverter power input (P load DC), the inverter power output (P load AC) and the inverter efficiency is depicted in Figure 10.

The average efficiency of inverter is $82.84 \%$. The inverter has a maximum factory efficiency of $94 \%$, according to the inverter specification. The inverter will suffer damage if there is an overload beyond the inverter's ability to meet the load requirements. Therefore, the inverter strive which could trigger the damage to its constituent components.

To find out the performance of the solar power plant, the calculation is conducted by multiplying the entire efficiency of each of the components efficiency. The calculation confirms that the photovoltaic array efficiency, inverter efficiency, battery efficiency, solar charge controller (SSC) are $10.78 \%, 82.84 \%, 86 \%$ and $88 \%$, respectively. Obtained total efficiency is $8.05 \%$.

The overall performance of solar power plant is depicted in the Sankey diagram, which is shown the amount of power entering and leaving the system, given in Figure 11. Only $10.78 \%$ of solar energy could be converted to the electrical power. Aside from the influence of solar irradiance, surface temperature and ambient temperature, the type of the PV establishes the PV efficiency. This system utilizes Poly-crystalline PV having efficiency of $14.13 \%$ and a tolerance of performance of $\pm 2 \%$. The output power which is used by the load is $7.31 \%$ and the remaining $0.74 \%$ of the total input power is stored in the battery system. The losses causing by charging proses and operation condition is relatively small, i.e. $1.27 \%$ and $1.43 \%$ respectively.

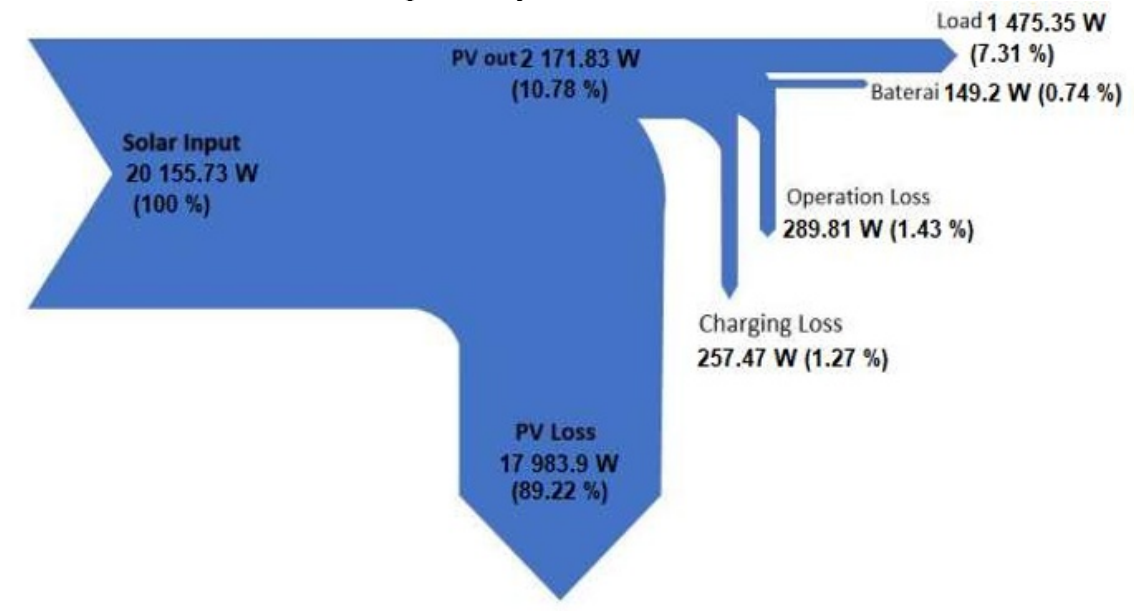

Fig. 11. Sankey diagram.

\section{Conclusion}

Data analysis and discussion of monitoring and performance of solar power plants in the ITS Engineering Physics Department has been carried out using a microcontroller and 
Raspberry Pi. Monitoring data is displayed on the LCD as the interface and sent to the Raspberry Pi to be uploaded to the website and stored as a database. After performance analysis using data from datalogger and irradiance, the solar power plants has a total efficiency of $6.77 \%$ with photovoltaic array efficiency of $10.78 \%$, inverter efficiency of $82.84 \%$, solar charge controller efficiency of $88 \%$ and battery efficiency is $86 \%$. From the load requirement to continue to operate using power from solar power plants, the power generated is able to meet the load needs to operate for $12 \mathrm{~h}$. Within this result, it can be concluded that real-time monitoring based on a microcontroller and Raspberry Pi could be implemented in PV tower for laboratory scale to optimized the device using.

Authors would like express the gratitude LPPM ITS for funding 1613/PKS/ITS/2019 the current research under the scheme of Department Research 2019. Authors also would like to thank all member of Energy Engineering and Environtmental Conditioning Laboratory, Department of Engineering Physics, ITS for their contributions to this work.

\section{References}

1. International Renewable Energy Agency. Perspectives for the energy investment needs for a low-carbon energy system. [Online] from

https://irena.org/publications/2017/Mar/Perspectives-for-the-energy-transition-

Investment-needs-for-a-low-carbon-energy-

system?utm_content=buffer9d50e\&utm_medium =social\&utm_source=twitter.com\&u tm_campaign=buffer (2017). [Accessed on July 7, 2020].

2. President of Indonesia, Peraturan Preslden Republlk Indonesia Nomor 22 Tahun 2017 Tentang Rencana Umum Energi Nasional. [Regulation of President of Republic of Indonesia Number 22 of 2017 Concerning National Energy General Plan]. Jakarta: President of Indonesia (2017). [in Bahasa Indonesia].

https://www.esdm.go.id/assets/media/content/content-rencana-umum-energi-nasionalruen.pdf

3. A.R. Rois, G. Nugroho, C. Budiono, Jurnal Teknik POMITS, 1-8(2016). http://digilib.its.ac.id/public/ITS-paper-41080-2410100071-paper.pdf)

4. Z.A. Kamaruzzaman, A. Mohamed, H. Shareef, Przeglad Elektrotechniczny, 91,6:134-138(2015). https://sigma-not.pl/publikacja-91611-2015-6.html

5. J.M. Paredes-Parra, A. Mateo-Aroca, G. Silvente-Niñirola, M.C. Bueso, Á. MolinaGarcía, Energies, 11,11:3051(2018). https://doi.org/10.3390/en11113051

6. R. Muttaqin, "Analisa Performansi dan Monitoring Pembangkit Listrik Tenaga Surya di Departemen Teknik Fisika FTI-ITS," [Performance Analysis and Monitoring of Solar Power Plants in the FTI-ITS Physics Engineering Department] [Undergraduate Thesis] Physic Engineering Department, Institut Teknologi Sepuluh Nopember (2017). [in Bahasa Indonesia]. http://repository.its.ac.id/47444/

7. I. Colak, S. Sagiroglu, G. Fulli, M. Yesilbudak, Renew. Sustain. Energy Rev., 54:396405(2016).

https://www.sciencedirect.com/science/article/pii/S1364032115011156?via\%3Dihub

8. M. Fuentes, M. Vivar, J.M. Burgos, J. Aguilera, J.A. Vacas, Sol. Energy Mater. Sol. Cells, 130:529-543(2014).

https://www.researchgate.net/publication/267394328 Design_of_an_accurate lowcost_autonomous data_logger_for_PV system monitoring using Arduino TM that complies_with_IEC_standards

9. L. Chhaya, P. Sharma, G. Bhagwatikar, A. Kumar, Indian J. Sci. Technol., 9,43: $1-5(2016)$. 
https://indjst.org/articles/design-and-implementation-of-remote-wireless-monitoringand-control-of-smart-power-system-using-personal-area-network

10. M. Nkoloma, M. Zennaro, A. Bagula, SM 2: Solar monitoring system in Malawi. Paper Presented in Proceeding of ITU Kaleidoscope 2011 (Cape Town, South Africa, 2011). https://ieeexplore.ieee.org/document/6144215

11. E. Kabalci, A. Gorgun, Y. Kabalci, Design and implementation of a renewable energy monitoring system. Paper presented in 4th International Conference on Power Engineering, Energy and Electrical Drives (Istanbul, Turkey, 2013). https://ieeexplore.ieee.org/stamp/stamp.jsp?tp=\&arnumber $=6635759$

12. P. Papageorgas, D. Piromalis, K. Antonakoglou, G. Vokas, D. Tseles, K.G. Arvanitis, Energy Procedia, 36:535-545(2013). https://www.sciencedirect.com/science/article/pii/S187661021301148X

13. A. Meliones, A. Nouvaki, Applied Computing and Informatics, 10,1-2:14-37(2014). https://www.sciencedirect.com/science/article/pii/S2210832714000118

14. R.C. Pambudi, R. Hantoro, H. Cordova, Jurnal Teknik ITS, 7,1:(2018). http://ejurnal.its.ac.id/index.php/teknik/article/view/27827

15. Y. Wang, International Journal of Online and Biomedical Engineering, 13,11:128135(2017). https://online-journals.org/index.php/i-joe/article/view/7749

16. E. Radziemska, International Journal of Photoenergy, 2009,732093:1-6(2009). https://www.hindawi.com/journals/ijp/2009/732093/ 